\title{
Rapid changes in concentrations of essential elements in organs of rats exposed to methylmercury chloride and mercuric chloride as shown by simultaneous multielemental analysis
}

\author{
Hajime Muto, Masayuki Shinada, Kazuko Tokuta, Yukio Takizawa
}

\begin{abstract}
An in vivo study of rats given a dominant lethal dose of methylmercury chloride (MMC) or mercuric chloride $\left(\mathrm{HgCl}_{2}\right)$ was conducted to elucidate the rapid biotransformation of essential elements. The elements were measured by inductively coupled plasma atomic emission spectrometry. For the rat brain $\mathrm{Zn}$ concentrations were higher, in the MMC group than in the $\mathrm{HgCl}_{2}$ and control groups. The highest $\mathrm{Cu}$ concentration was found in $\mathrm{HgCl}_{2}$ dosed rat liver. For the rat kidney the highest $\mathrm{Zn}$ concentration was seen in the MMC group. From principal component analysis on the time dependent behaviour of each element in rat organs, characteristics specific to $\mathrm{Cu}$ in the liver and kidney and $\mathrm{Mn}$ in the brain were found after exposure to $\mathbf{H g C l}_{2}$ and $\mathrm{Ca}$ and $\mathrm{Zn}$ in the brain after exposure to MMC.
\end{abstract}

Previous studies have suggested that the toxic effects of methylmercury are a result of its ability to rapidly cross permeability barriers such as the blood brain barrier. ${ }^{1}$ Inorganic mercury is also transported through lipid bilayer membranes. ${ }^{2}$

Monitoring the phase transition temperature and the permeability of phospholipid bilayer vesicles, Bevan et al reported that the relative effectiveness of the metal ions, in decreasing order, was $\mathrm{Zn}^{2+}>\mathrm{Cd}^{2+}$ $>\mathrm{Hg}^{2+} \gg \mathrm{Ca}^{2+}>\mathrm{Mg}^{2+}$. These interactions of $\mathrm{Zn}^{2+}$, $\mathrm{Cd}^{2+}$, and $\mathrm{Hg}^{2+}$ with phospholipids in membranes may be physiologically significant. ${ }^{3}$ It has also been found that association of mercury with metallothionein results in altered amounts of $\mathrm{Zn}$ and $\mathrm{Cu} .^{4-6}$ Furthermore, the addition of $\mathrm{Hg}^{2+}$ to loaded kidney mitochondria induces the fast release of accumulated

Environmental Research Center, Akíta University, Hondo 1-1-1, Akita 010, Japan

H Muto

Department of Public Health, Akita University School of Medicine, Hondo 1-1-1, Akita 010, Japan M Shinada, K Tokuta, Y Takizawa cation and the $\mathrm{Ca}^{2+}$ efflux exhibits kinetics that depend on the extent of the binding of $\mathbf{H g}^{2+}$ to the membrane. ${ }^{7}$

On the other hand, membrane lipid peroxidation and free radical formation induced by mercury exposure cause damage to biological membranes. ${ }^{8-10}$ Of the many physiological effects of mercury, it has been shown to alter the metabolism of some of the essential elements including $\mathrm{Zn}^{11-14}$

We report here the rapid concentration changes of essential elements in rat organs after a dominant lethal dose of mercury.

\section{Materials and methods \\ CHEMICALS}

All chemicals were of reagent grade quality or provided specifically for trace element analysis and were obtained from Wako Pure Chemical Industries Ltd, Osaka, Japan. Standard stock solutions of $\mathrm{Na}$, $\mathrm{K}, \mathrm{Mg}, \mathrm{Ca}, \mathrm{Fe}, \mathrm{Mn}, \mathrm{Al}, \mathrm{Cu}, \mathrm{Zn}$, and $\mathrm{Hg}$ were prepared from $1000 \mathrm{ppm}$ certified atomic absorption reference solutions.

\section{ANIMAL STUDIES}

Male Wistar rats weighing 180 to $220 \mathrm{~g}$ were housed in stainless steel cages with five or six animals a cage. They were given unlimited commercial pellet diet and tap water for at least one week before use and during the study. Twelve rats were used for each of the methylmercury chloride (MMC) dosed, mercuric chloride $\left(\mathrm{HgCl}_{2}\right)$ dosed, and control groups. Each $1 \mathrm{ml}$ of $M M C(10 \mathrm{mg} / \mathrm{kg} \mathrm{b} \mathrm{w})$ premixed with L-cysteine solution ( $3 \mathrm{mg} / \mathrm{ml} 0.9 \%$ saline), $\mathrm{HgCl}_{2}(1 \mathrm{mg} / \mathrm{kg} \mathrm{bw})$ dissolved in $0.9 \%$ saline solution, or $0.9 \%$ saline solution alone (control) was injected subcutaneously into the rats by a single dose. Three rats were selected randomly from each group at three, six, 12, and 24 hours after injection and killed at these times. The brain, liver, and kidneys were excised, rinsed in distilled water, and homogenised at high speed in an ultrahomogeniser (Physcotron NS-50, Ikemoto Sci Technol Co Ltd, Japan) until a smooth homogenate was obtained. The homogenised sample, 1-10 g depending on the individual sample size, was weighed into a metal free 
$100 \mathrm{ml}$ beaker. In a chemical clean hood 1:1 concentrated $\mathrm{HNO}_{3} / \mathrm{HClO}_{4}(10 \mathrm{ml})$ was added to the sample and the beaker, covered with a watch glass, was placed on a hot plate (HK-41, Yamato Sci Co Ltd, Japan). The hot plate was maintained at $150^{\circ} \mathrm{C}$ and the contents of the beaker allowed to simmer stirring frequently with a glass rod. This avoided loss of sample by overfrothing. The solution was then taken down to near dryness indicated by foaming on the bottom of the beaker, $11 \cdot 6 \% \mathrm{HCl} / 2 \cdot 8 \% \mathrm{HNO}_{3}(3 \mathrm{ml})$ was added, and the solution heated at $100^{\circ} \mathrm{C}$ for five minutes. After cooling until just warm to the touch, the digested sample was carefully transferred through filter paper (5A, Toyo Roshi Kaisha Ltd, Japan) into a calibrated test tube. The volume was adjusted to $10 \mathrm{ml}$ and split for each measurement.

\section{SAMPLE ANALYSIS}

All glassware was decontaminated by cleaning with a neutral detergent, rinsing with hot water to remove all detergent, washing with $\mathrm{HNO}_{3}$ diluted $1: 1$ with water, and rinsing with deionised water at least five times.

A flame spectrophotometer ((FS), Hitachi 180-30 type (Japan)) was employed for measurement of $\mathrm{Na}$ and $\mathrm{K}$. The operating conditions were: wavelengths of $589.0 \mathrm{~nm}$ for $\mathrm{Na}, 766.5 \mathrm{~nm}$ for $\mathrm{K}$; slit setting 0.2 $\mathrm{nm}$; flame air-acetylene. Gas chromatography for MMC measurement was performed with a Shimadzu GC-8A (Japan) gas chromatograph equipped with an electron capture detector (GC-ECD) and a glass column $(3 \mathrm{~mm} \times 1 \mathrm{~m}$ packed with Shimalite uniport ( $60-80 \mathrm{mesh}$ ) coated with DEGS$\mathrm{Hg}$ ). Column and injection/detector temperatures were $160^{\circ} \mathrm{C}$ and $230^{\circ} \mathrm{C}$, respectively. Highly purified nitrogen was used as the carrier gas at a flow rate of 60 $\mathrm{ml} / \mathrm{min}$. Total mercury $(\mathrm{T}-\mathrm{Hg}$ ) analysis was carried out by cold vapour atomic absorption spectrometry (AAS).

Inductively coupled plasma atomic emission spectrometry (ICP-AES, Shimadzu ICPQ-1000, Japan, equipped with a professional computer) was used for the measurement of major, minor, and trace elements in rat organs. The operating conditions were power supply, $1.2 \mathrm{KW}$; coolant argon flow 11.3 $1 / \mathrm{min}$; carrier argon flow, $1.01 / \mathrm{min}$; plasma argon flow, $1.4 \mathrm{l} / \mathrm{min}$; nebulizer, concentric; plasma viewing height $15 \mathrm{~mm}$; rate of introduction of sample, $2.3 \mathrm{ml} /$ min (in demineralised water); plate current $0.75 \mathrm{~A}$; integration time 20 seconds; analytical lines, $\mathbf{M g}$ $279.55 \mathrm{~nm}$, Ca $393.37 \mathrm{~nm}, \mathrm{Fe} 259.94 \mathrm{~nm}, \mathrm{Mn} 257.61$ $\mathrm{nm}, \mathrm{Al} 396 \cdot 15 \mathrm{~nm}, \mathrm{Cu} 324 \cdot 75, \mathrm{Zn} 202 \cdot 55 \mathrm{~nm}$.

The plasma was ignited according to manufacture's instructions, and the parameters set as previously outlined. The sample solutions were aspirated until the method file was completed. After measurement of every sample or standard, deionised water was aspirated for about one minute to rinse the spray chamber and injector tube. For measurement of major elements the sample solution was diluted before analysis, and minor and trace elements were generally determined without dilution. To avoid effects of solids on the nebulizer (H-57 type) system and to minimise possible background and matrix interference owing to high concentration of acids, the sample was diluted with deionised water when required. Each element wavelength was calibrated using a single element standard. Calibration curves for each element were made by using four different standard solutions (including $0 \mu \mathrm{g} / \mathrm{ml}$ ). Interference effects of the major elements $\mathrm{Na}, \mathrm{K}$, and $\mathrm{Mg}$ on the ICP-AES measurement were tested at four concentrations $(0,250,500$, and $1000 \mu \mathrm{g} / \mathrm{ml})$ in solutions containing each of six minor and trace elements of $1 \mu \mathrm{g} / \mathrm{ml}$ concentration.

\section{DATA ANALYSIS}

Differences in the time dependent changes of various essential elements in mercury exposed rat organs in comparison with controls were assessed for significance by analysis of covariance to test the difference on the population regression line of the element. Significance was evaluated at $p<0.05, p<$ 0.025 , and $\mathrm{p}<0.01$.

From the principal component analysis (PCA), the factor contribution and factor score of each element were calculated on each exposed group by the correlation coefficient matrix including the time course data of all elements analysed in the three organs.

\section{Results}

Table 1 summarises the concentrations of various major, minor, and trace elements in the organs from $\mathrm{HgCl}_{2}$ and $\mathrm{MMC}$ dosed rats and controls. These data were obtained from a time course study three, six, 12 , and 24 hours after dosing. Total mercury concentrations were highest in the rat kidney after treatment with $\mathrm{MMC}$ and $\mathrm{HgCl}_{2}$ and these values were significantly greater compared with those in controls and also with concentrations in other organs. For the brain $\mathrm{Na}$ concentrations were lower in the $\mathrm{HgCl}_{2}$ group than in the $\mathrm{MMC}$ and control groups, and $\mathrm{K}$ concentrations were highest in the MMC group. The brain concentrations of $\mathrm{Ca}$ and $\mathrm{Mn}$ in the $\mathrm{HgCl}_{2}$ group and brain concentrations of $\mathrm{Cu}$ and $\mathrm{Zn}$ in the MMC group were also higher. For $\mathrm{HgCl}_{2}$ exposed rat liver higher $\mathrm{Cu}$ concentrations were found, compared with the MMC and control groups. For the kidney Cu concentrations were significantly higher in the $\mathrm{HgCl}_{2}$ group and $\mathrm{Zn}$ concentrations were higher in the MMC group. Also, higher $\mathrm{Na}$ and lower $\mathrm{K}$ concentrations were found in the $\mathrm{HgCl}_{2}$ group compared with the MMC and control groups. Figures 1 and 2 show the concentration changes with time of $\mathrm{Ca}$ 
Table 1 Concentration changes of various major, minor, and trace elements in $\mathrm{HgCl}_{2}$ and $\mathrm{MMC}$ exposed rat organs

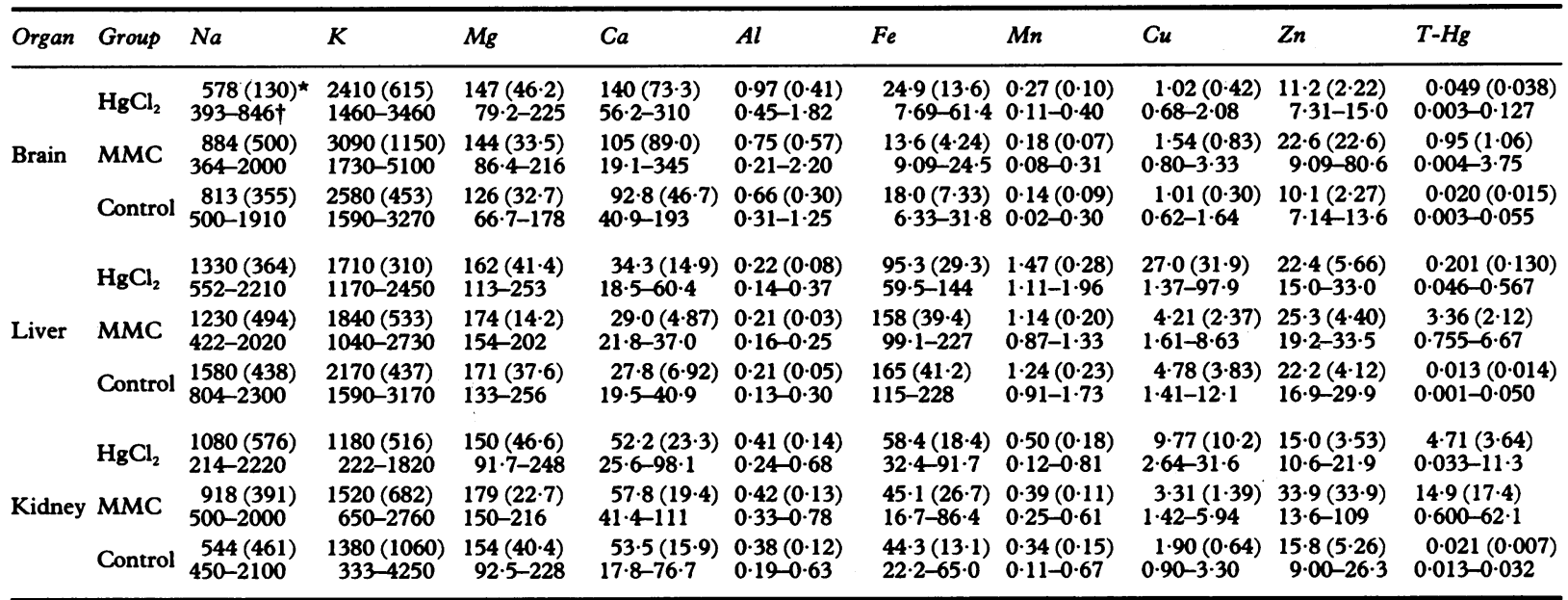

${ }^{\star}$ Mean (standard deviation) $\mu \mathrm{g} / \mathrm{g}$ wet tissue.

†Range.

Time after

dosing $(\mathrm{h})$
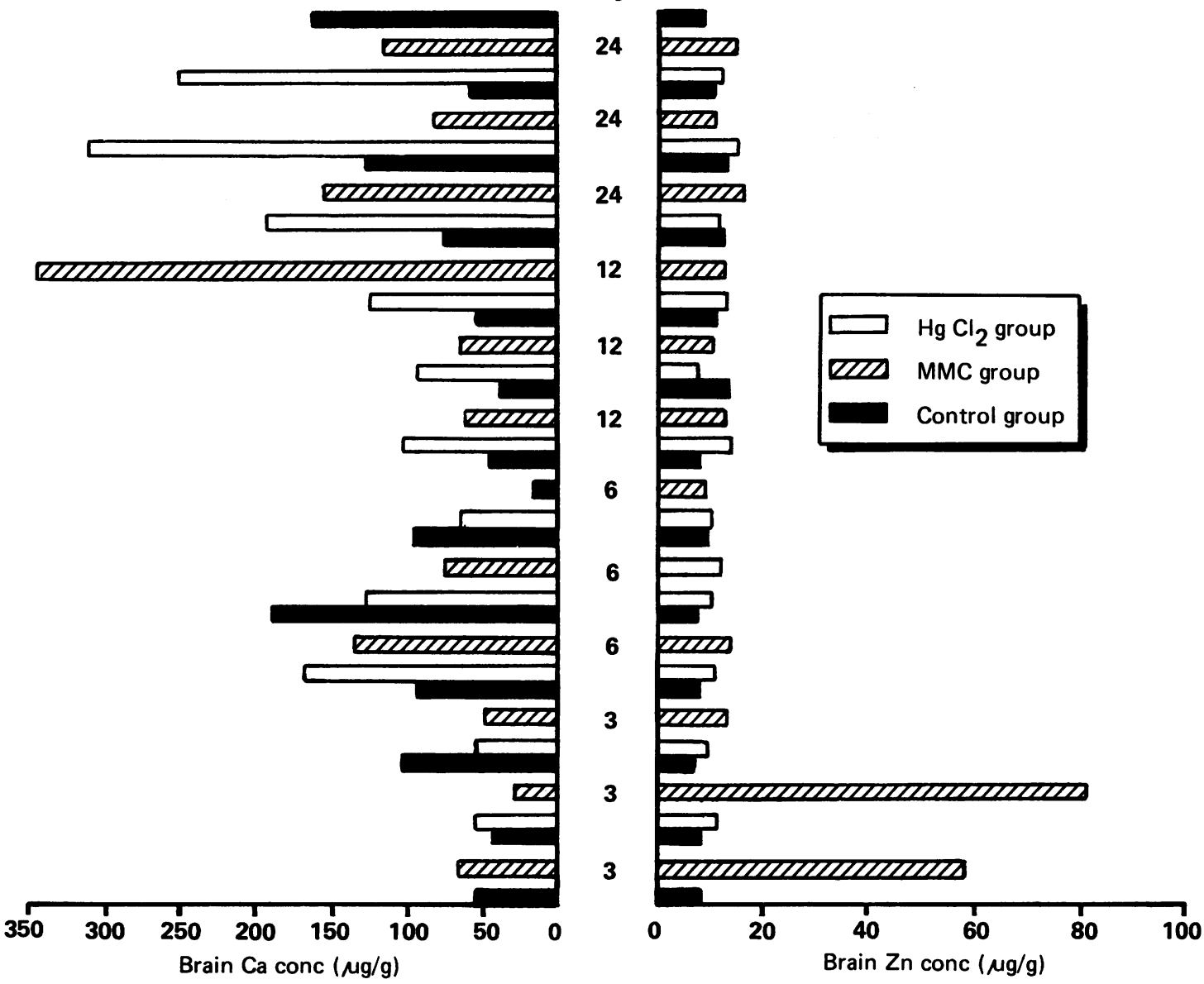

Figure 1 Concentration changes of $\mathrm{Ca}$ and $\mathrm{Zn}$ in the mercury exposed rat brain. Three values for each element were obtained for each treatment and time. 


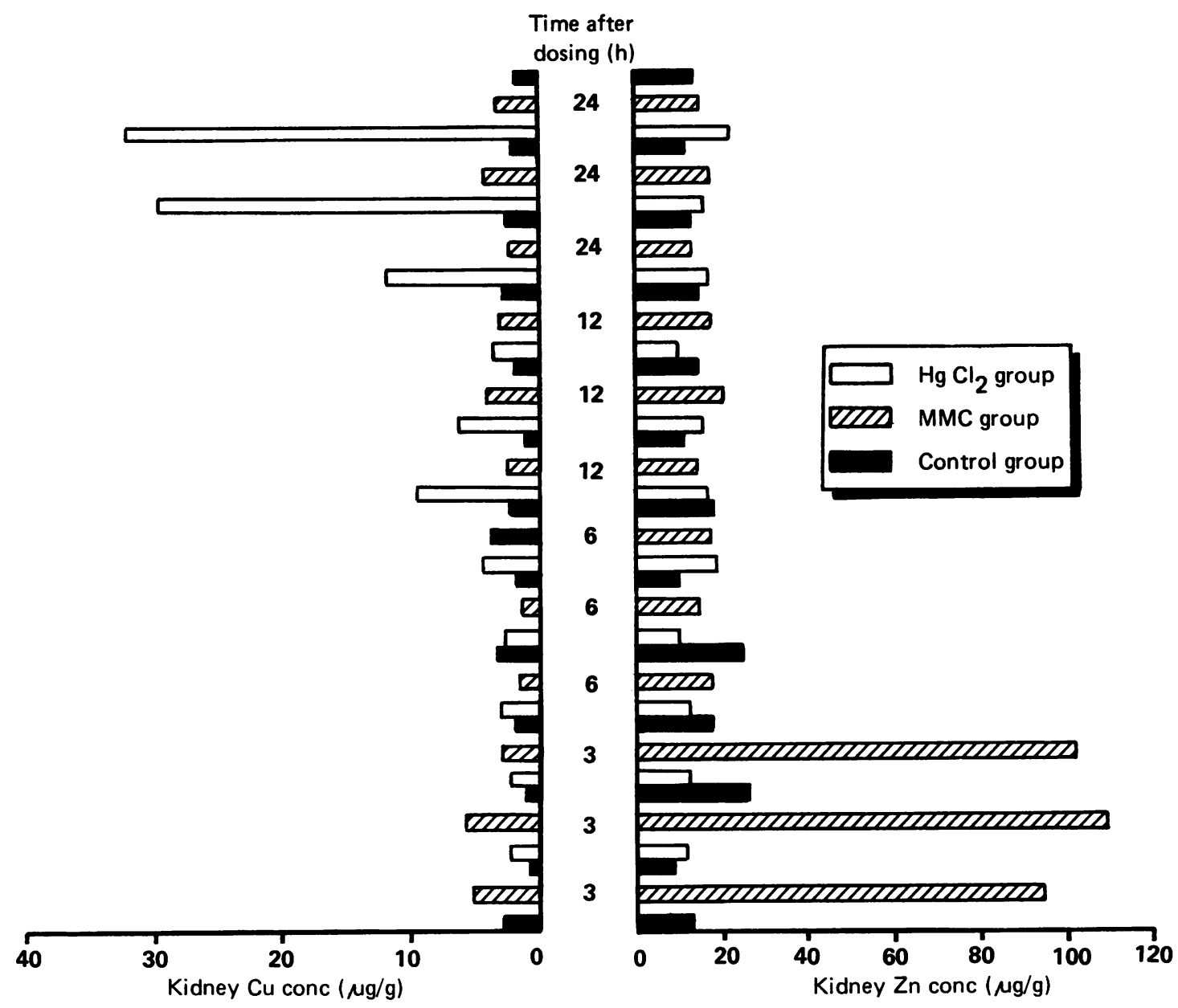

Figure 2 Concentration changes of $\mathrm{Cu}$ and $\mathrm{Zn}$ in the mercury exposed rat kidney. Three values for each element were obtained for each treatment and time.

and $\mathrm{Zn}$ in rat brains and of $\mathrm{Cu}$ and $\mathrm{Zn}$ in rat kidneys from the two treated groups and controls.

Table 2 shows the results from the analyses of covariance on population regression lines of various elements in the three organs studied. Major elements, $\mathrm{Na}, \mathrm{K}$, and $\mathrm{Ca}$, in organs exposed to a dominant lethal dose of $\mathrm{HgCl}_{2}$ significantly increased in concentration (other than $\mathrm{K}$ in the liver). This was particularly so for all elements in the kidney. Some significant increases or decreases in concentrations of trace and minor elements such as $\mathrm{Cu}, \mathrm{Zn}, \mathrm{Mn}$, and $\mathrm{Fe}$ were shown for both $\mathrm{HgCl}_{2}$ and $\mathrm{MMC}$ groups. Also, the elements $\mathrm{Mg}, \mathrm{Ca}, \mathrm{Al}$, and $\mathrm{Cu}$ in three organs exposed to $\mathrm{HgCl}_{2}$ had comparatively good correlations with controls.

\section{Discussion}

Our present data (table 1) were comparable with reference data on concentration of essential elements in male Sprague Dawley rat tissues, bovine liver, etc. ${ }^{11} 15-18$ Some essential elements in mercury exposed groups were shown to have significant changes in their concentrations in rat organs. For the rat kidney and brain rapid uptake of $\mathrm{Zn}$ within three hours was induced by exposure to MMC, and time dependence of increased concentrations of $\mathrm{Cu}$ was shown after $\mathrm{HgCl}_{2}$ dosing. A significant increase in $\mathrm{Cu}$ concentration was also shown after exposure to MMC, although this was not time-dependent. To define the changes more clearly PCA was used. Figures $3\left(\mathrm{HgCl}_{2}\right.$ exposure) and 4 (MMC exposure) 
Table 2 Results from analyses of covariance on population regression lines of various elements in rat organs between mercury exposed and control groups

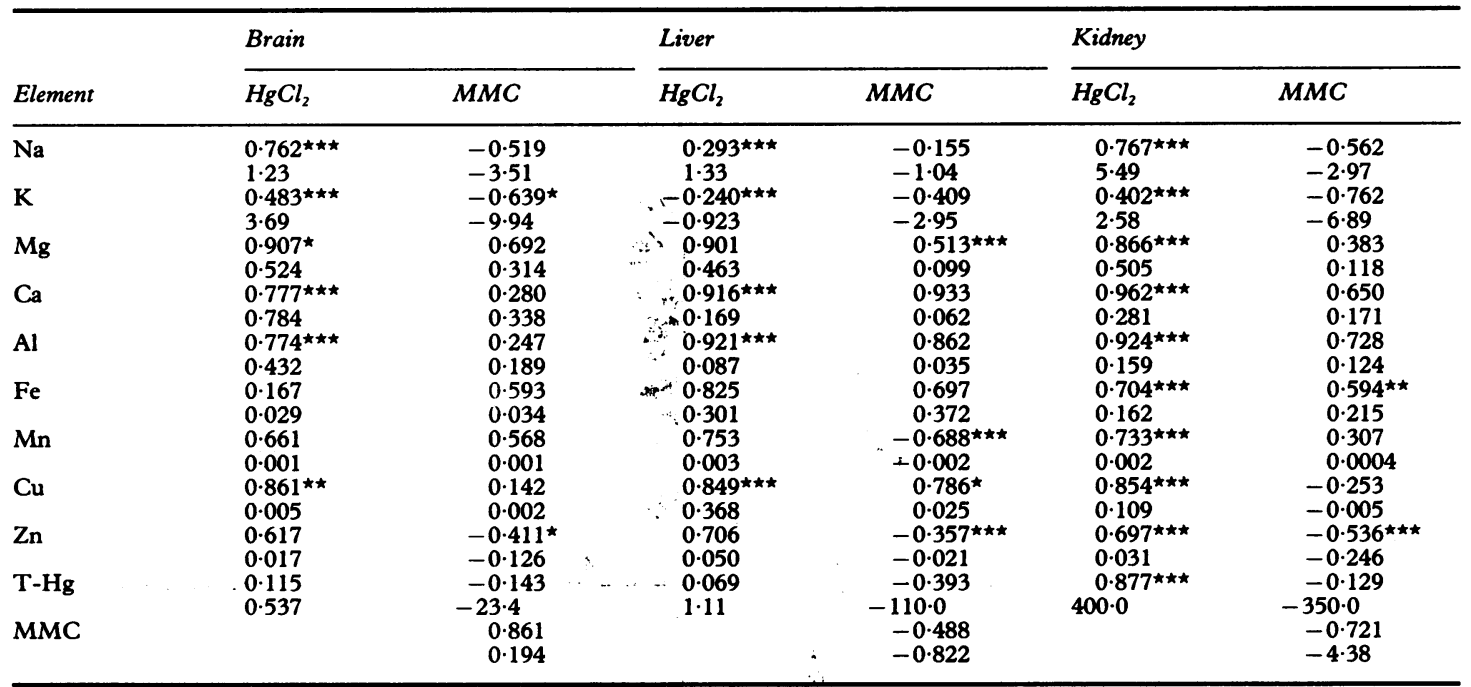

${ }^{\star} \mathrm{p}<0.05,{ }^{\star \star} \mathrm{p}<0.025, \star \star \star \mathrm{p}<0.01$.

The test of the difference for each element was conducted by using two population regression lines. The population of each element was constituted by all 12 values from four time points of three, six, 12, and 24 hours after dosing. The values show the correlation coefficients (above) between mercury exposed and control groups for essential elements and the regression coefficients (below) of mercury exposed groups.

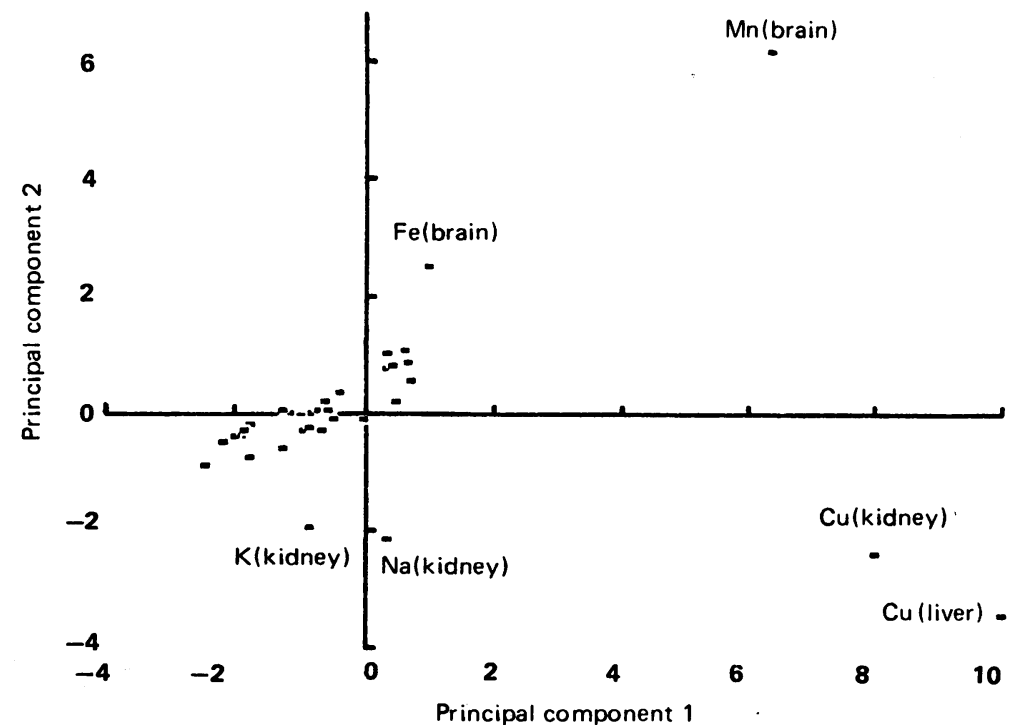

Figure 3 Principal component analysis score projection on PC1-PC2 for essential elements in $\mathrm{HgCl}_{2}$ exposed rat organs. Each of three elemental concentration data from a data point in the $\mathrm{HgCl}_{2}$ exposed group was divided by a mean value of three control data and used as input data. The corrected data numbers for each element in each organ were 12. The PCA was performed using the correlation matrix. 


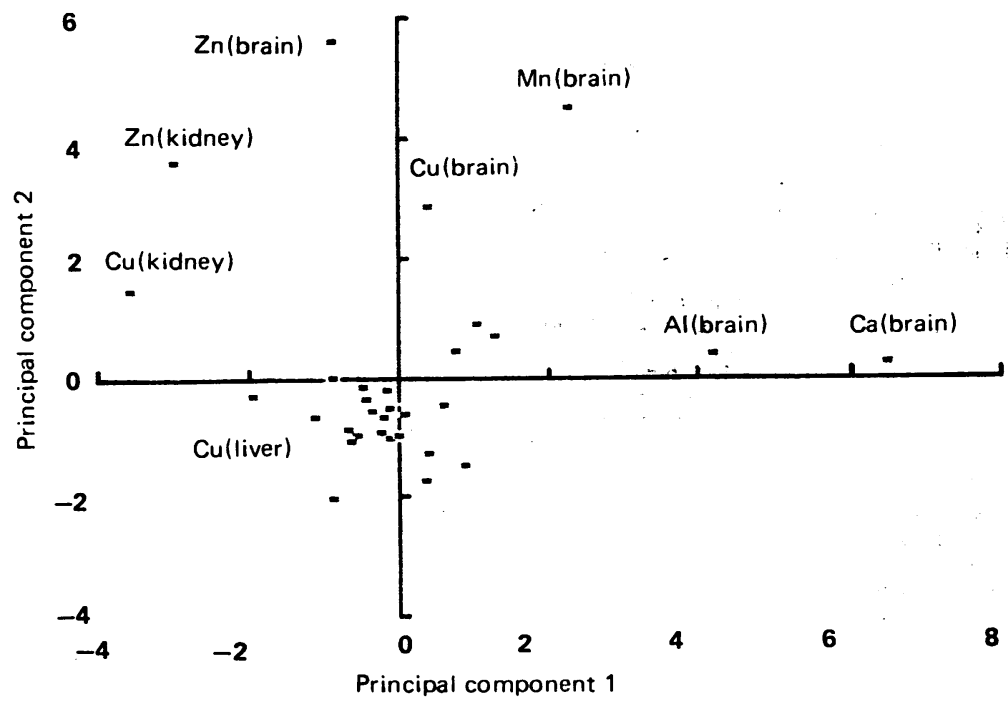

Figure 4 Principal component analysis score projection on PC1-PC2 for essential elements in MMC exposed rat organs. Each of three elemental concentration data from a data point in the MMC exposed group was divided by a mean value of three control data and used as input data. The corrected data numbers for each element in each organ were 12. The PCA was performed using the correlation matrix.

show the PCA score projections, and suggest the time dependent characteristics of elements in rat organs induced by dosing with mercury. Figure 3 shows that several elements have abnormal scores on PC1-PC2 space, calculating the first factor contribution of $60 \%$ and the cumulative factor contributions of $88 \%$ up to the third factors. Concentrations of $\mathrm{Cu}$ in the liver and kidney and $\mathrm{Mn}$ in the brain may have abnormal characteristics; the uptakes of $\mathrm{Cu}$ and $\mathrm{Mn}$ by these organs were significant as shown in tables 1 and 2 . Also, from a score projection on PC1-PC2 space for MMC exposure (fig 4) obtaining the cumulative factor contributions of $63 \%$ up to the third factors, $\mathrm{Ca}$ and $\mathrm{Zn}$ abnormalities with a wide variation appear to be considerable (see also table 1 and figure 1), although the abnormal scores of elements were not so clearly shown compared with some elements after exposure to $\mathrm{HgCl}_{2}$. A longer term study of rats exposed to MMC may more clearly define the apparently affected behaviours of $\mathrm{Zn}$ in the kidney, $\mathrm{Cu}$ in the brain and liver, and $\mathrm{Mn}$ in the brain.

Bogden et al have suggested that the increased concentrations of $\mathrm{Cu}$ in the kidney may be related to the induction of renal metallothionein synthesis by mercury ${ }^{11}$; the addition of high concentrations of mercury to diets for rats causes the accumulation of mercury in renal metallothionein and causes $\mathrm{Zn}$ to accumulate in it. ${ }^{19}$ The concept that removal of metal is an important step in the degradation of metalloth- ionein in vivo has also been discussed. ${ }^{20-22}$ Funk et al have reported that the in vitro affinity of elements for metallothionein is $\mathrm{Zn}<\mathrm{Cd}<\mathrm{Cu}<\mathrm{Hg}^{23}$ Mercury is thought to produce its renal toxicity by combining with plasma membrane sulphydryl groups in proximal tubular epithelium to form mercaptide bonds. ${ }^{24}$ Furthermore, Chavez et al have reported that $\mathrm{Hg}^{2+}$ at concentrations higher than $5 \mu \mathrm{M}$ induces $\mathrm{Ca}^{2+}$ efflux and the pathways of kidney mitochondrial $\mathrm{Ca}^{2+}$ release are associated with the binding of $\mathrm{Hg}^{2+}$ to membrane proteins. ${ }^{25}$

From our statistical results the elements $\mathrm{Na}, \mathrm{K}$, $\mathrm{Ca}, \mathrm{Mn}, \mathrm{Cu}$, and $\mathrm{Zn}$ showed significant concentration changes with time after a dominant lethal dosing with mercury compounds. Particularly, it was found by PCA that $\mathrm{Cu}$ in the liver and kidney and $\mathrm{Mn}$ in the brain after $\mathrm{HgCl}_{2}$ exposure and $\mathrm{Ca}$ and $\mathrm{Zn}$ in the brain after MMC exposure exhibited specific behaviours at an early stage in three rat organs, compared with other essential elements as measured by simultaneous multielemental analysis.

We thank Miss Nakayo Ohmori and Mr Yoshinori Okamura for technical assistance.

Requests for reprints to: Hajime Muto, Environmental Research Center, Akita University, Hondo 1-1-1, Akita 010, Japan. 
1 Magos L. Uptake of mercury by the brain. Br J Ind Med 1968;25:315-8.

2 Gutknecht $\mathrm{J}$. Inorganic mercury $\left(\mathrm{Hg}^{2+}\right)$ transport through lipid bilayer membranes. J Membr Biol 1981;61:61-6.

3 Bevan DR, Worrell WJ, Barfield KD. The interaction of $\mathrm{Ca}^{2+}$, $\mathrm{Mg}^{2+}, \mathrm{Zn}^{2+}, \mathrm{Cd}^{2+}$, and $\mathbf{H g}^{2+}$ with phospholipid bilayer vesicles. Colloids and Surfaces 1983;6:365-76.

4 Brady FO, Webb $M$. Metabolism of zinc and copper in the neonate. J Biol Chem 1981;256:3931-5.

5 Holt D, Magos L, Webb M. The interaction of cadmiuminduced rat renal metallothionein with bivalent mercury in vitro. Chem-Biol Interact 1980;32:125-36.

6 Webb M, Cain K. Functions of metallothionein. Biochem Pharmacol 1982;31:137-42.

7 Chavez E, Zazueta C, Diaz E, Holquin JA. Characterization by $\mathrm{Hg}^{2+}$ of two different pathways for mitochondrial $\mathrm{Ca}^{2+}$ release. Biochim Biophys Acta 1989;986:27-32.

8 Ribarov SR, Benov LC, Marcova VL, Benchev IC. Hemoglobin-catalyzed lipid peroxidation in the presence of mercuric chloride. Chem-Biol Interact 1983;45:105-12.

9 Tominaga $K$. Effects of dietary polyunsaturated fatty acids on lipid peroxidation and accumulation of mercury in rat tissues. Medical Journal of Kagoshima University 1982;39:1-12.

10 Doni MG. Antioxidant defence and protection of cell membranes from lipid peroxidation. Agents Actions 1987;22:355-6.

11 Bogden JD, Kemp FW, Troiano RA, Jortner DS, Timpone C, Giuliani D. Effects of mercuric chloride and methyl mercury chloride exposure on tissue concentrations of six essential minerals. Environ Res 1980;21:350-9.

12 Sandstead $\mathrm{HH}$. Nutrient interactions with toxic elements. In: Goyer RA, Mehlman MA, ed. Toxicology of trace elements. Washington: Hemisphere Publishing Corporation, 1977: 241-56.

13 Barfield KD, Bevan DR. Fusion of phospholipid vesicles induced by $\mathrm{Zn}^{2+}, \mathrm{Cd}^{2+}$, and $\mathrm{Hg}^{2+}$. Biochem Biophys Res Commun 1985;128:389-95.

14 Takeuchi $T$, Nakano $Y$, Aoki A, Ohmori S, Tsukatani $T$. Comparisons of elemental concentrations in hair of the inhabitants of heavy metal polluted areas with those of normal Japanese. Journal of Radioanalytical and Nuclear Chemistry 1987;112:259-72.
15 Shiraishi K, Tanaka G, Kawamura H. Simultaneous multielement analysis of various human tissues by inductivelycoupled plasma atomic-emission spectrometry. Talanta 1986;33:861-5.

16 Que Hee SS, Boyle JR. Simultaneous multielemental analysis of some environmental and biological samples by inductively coupled plasma atomic emission spectrometry. Anal Chem 1988;60:1033-42.

17 Muramatsu Y, Parr RM. Concentrations of some trace elements in hair, liver and kidney from autopsy subjects-relationship between hair and internal organs. Sci Total Environ 1988;76:29-40.

18 Fishbein L. Perspectives of analysis of carcinogenic and mutagenic metals in biological samples. International Journal of Environmental Analytical Chemistry 1987;28:21-69.

19 Whanger PD, Deagen JT. Effects of dietary mercury level and cadmium on rat tissue metallothionein: Mercury binding and influences on zinc. Environ Res 1983;30:372-80.

20 Lee YH, Shaikh ZA, Tohyama C. Urinary metallothionein and tissue metal levels of rat injected with cadmium, mercury, lead, copper or zinc. Toxicology 1983;27:337-45.

21 Bremner I, Mehra RK. Metallothionein: Some aspects of its structure and function with special regard to its involvement in copper and zinc metabolism. Chemica Scripta 1983;21: $117-21$.

22 Sato $M$, Nagai $Y$, Bremner I. Urinary excretion of metallothionein-1 and its degradation product in rats treated with cadmium, copper, zinc or mercury. Toxicology 1989;56:23-33.

23 Funk AE, Day FA, Bardy FO. Displacement of zinc and copper from copper-induced metallothionein by cadmium and by mercury: in vivo and ex vivo studies. Comp Biochem Physiol [C] 1987;86:1-6.

24 Rizzuto R, Pitton G, Azzone GF. Effect of $\mathrm{Ca}^{2+}$, peroxides, $\mathrm{SH}$ reagents, phosphate and aging on the permeability of mitochondrial membranes. Eur J Biochem 1987;162:239-49.

25 Chavez E, Holquin JA. Mitochondrial calcium release as induced by $\mathrm{Hg}^{2+}$. J Biol Chem 1988;263:3582-7.

Accepted 12 November 1990
The British Journal of Industrial Medicine welcomes correspondence relating to any of the material appearing in the journal. Results from preliminary or small scale studies may also be published in the correspondence column if this seems appropriate. Letters should be not more than $\mathbf{5 0 0}$ words in length and contain a minimum of references. Table and figures should be kept to an absolute minimum. Letters are accepted on the understanding that they may be subject to editorial revision and shortening.

The journal now also publishes editorials which are normally specially commissioned. The Editor welcomes suggestions regarding suitable topics; those wishing to submit an editorial, however, should do so only after discussion with the Editor. 